This is an open access article distributed under the terms of the Creative Commons BY-NC-ND Licence

\title{
Involvement of proline and non-protein thiols in response to low temperature and cadmium stresses in wheat
}

\author{
N. REPKINA*, V. TALANOVA, A. IGNATENKO, and A. TITOV \\ Institute of Biology, Karelian Research Centre, Russian Academy of Sciences, Petrozavodsk, 185910, Russia
}

\begin{abstract}
The aim of this study was to investigate the effects of low temperature $\left(4^{\circ} \mathrm{C}\right)$, cadmium sulphate $(100 \mu \mathrm{M})$, or their combination on content of free proline (Pro), glutathione (GSH), and phytochelatins (PCs) in wheat (Triticum aestivum L.) leaves. Results revealed an increase in proline and phytochelatins accumulation in leaves of wheat seedlings along with enhanced cold tolerance at the low temperature, $\mathrm{CdSO}_{4}$, and their combination. Moreover, there were increases in mRNA content of TaP5CS and TaPCS1 genes, encoding $\Delta^{1}$-pyrroline-5-carboxylate synthase (P5CS) and phytochelatin synthases (PCS), respectively. A rapid increase in glutathione content was found within $1 \mathrm{~h}$ of exposure to the low temperature and its combination with $\mathrm{CdSO}_{4}$, followed by a drop. However, upregulation of the TaGS1 gene, encoding glutathione synthetase (GS), was maintained during $7 \mathrm{~d}$. A significant decrease in glutathione content on the seventh day of exposure to the low temperature, $\mathrm{CdSO}_{4}$, and their combination was most probably due to its involvement in cadmium detoxification and/or in phytochelatin synthesis. Our data suggest that proline, glutathione, and phytochelatins may be important for plant tolerance to low temperature and cadmium stress in wheat.
\end{abstract}

Additional key words: glutathione, glutathione synthetase, phytochelatins, phytochelatin synthases, $\Delta^{1}$-pyrroline-5-carboxylate synthase.

\section{Introduction}

Plants in their natural environment are often subjected to various stresses, such as extreme temperatures, heavy metals, drought, salinity, etc., and thus have evolved a multitude of defense mechanisms to increase their tolerance (Nakabayashi and Saito 2015). Adaptation of plants to stresses is linked to mobilization of antioxidants including enzymes and non-enzymatic compounds such as proline, glutathione, tocopherols, flavonoids, and others (Waśkiewicz et al. 2014). Proline (Pro), as a multifunctional amino acid, has diverse roles in stress protection such as stabilization of proteins, subcellular structures and membranes, scavenging reactive oxygen species (ROS), and mediating shuttling chemical energy required for recovery from stress (Rejeb et al. 2014, Kaur and Asthir 2015). It has been demonstrated that Pro is synthesized from either glutamate or ornithine, whereas under stress conditions, the glutamate pathway usually dominates (Stein et al. 2011). Accumulation of Pro in response to various environmental stresses in plants has been well established (Kishor and Sreenivasulu 2014).

Glutathione $(\mathrm{GSH})$ is a thiol-containing lowmolecular-mass tripeptide ( $\gamma$-Glu-Cys-Gly) with multiple functions in plants (Noctor et al. 2012, Gill et al. 2013, Delorme-Hinoux et al. 2016). Besides the control of ROS accumulation, GSH takes part in the regulation of growth, development, cell cycle, gene expression, and protein activity due to its effect on redox state of the cells (Pivato et al. 2014, Diaz-Vivancos et al. 2015). This compound is also involved in storage and transport of sulphur, signal transduction, and enzymatic regulation (Anjum et al. 2012). Moreover, GSH plays an important role in plant adaptation to many environmental stresses such as drought, salinity, temperature extremes, heavy metal, etc. There are several possible ways for GSH to be involved in heavy metal tolerance: it protects cells from oxidative stress, and it is also a ligand for metal ions and so enables

Submitted 3 November 2017, last revision 31 May 2018, accepted 5 June 2018.

Abbreviations: f.m. - fresh mass; GS - glutathione synthetase; GSH - reduced glutathione; LT50 - temperature which induced death of $50 \%$ of palisade cells of leaf mesophyll; MDA - malondialdehyde; PCs - phytochelatins; PCS - phytochelatin synthases; Pro - free proline; ROS - reactive oxygen species.

Acknowledgements: The study was carried out under a state order (project No. 0221-2017-0051).

*Corresponding author; e-mail: nrt9@ya.ru 
their transport into the vacuole (Gallego et al. 2012). Furthermore, GSH is a substrate for synthesis of phytochelatins (PCs), which are directly involved in heavy metal detoxification (Pal and Rai 2010, Anjum et al. 2012). The PCs are small thiol peptides with the general structure $(\gamma \text {-Glu-Cys })_{n}$-Gly $(\mathrm{n}=2-11)$ (Pivato et al. 2014). Due to their ability to bind metals, PCs are generally considered to be essential cellular chelating agents, and so they contribute to metal tolerance by metal detoxification. In addition, PCs also play a role in the long-distance transport of metals including $\mathrm{Cd}$ (Chen et al. 2006). Moreover, an increase in PCs content has also been observed in response to salt, heat, and UV-B radiation (Zagorchev et al. 2013). Probably, the role of PCs may not be restricted to the chelation of metal ions, and their involvement in response to other abiotic stresses as antioxidants or proteins protectors can be proposed for further studies (Zagorchev et al. 2013).

Despite the fact that proline and non-protein thiols participate in cold and metal tolerance, their specific roles in plant adaptation to stresses are still debated. Moreover, the molecular and metabolic responses of plants to a combination of low temperature and cadmium cannot be directly extrapolated from plant responses to each of these individual stresses. However, to date there are no studies available on the role of low-molecular-mass protectors to the combined effect of different stress factors. For this reason, we analyzed the effect of low temperature, cadmium, and their combination on Pro, GSH, and PCs content and biosynthesis in wheat plants. The findings can improve our understanding of the mechanisms underlying plants tolerance to combined stresses.

\section{Materials and methods}

Seeds of winter wheat (Triticum aestivum L. cv. Moskovskaya 39) were purchased from the Tula Research Institute of Agriculture, Tula, Russia. Seedlings were cultivated on a Hoagland nutrient solution $(\mathrm{pH} 6.2$ to 6.4) in a growth chamber with a 14-h photoperiod, a photo-synthetic photon flux density of $180 \mu \mathrm{mol} \mathrm{m} \mathrm{m}^{-2} \mathrm{~s}^{-1}$, a temperature of $22{ }^{\circ} \mathrm{C}$ and a relative humidity of $60-70 \%$. Seven-day-old seedlings were exposed to a low temperature $\left(4^{\circ} \mathrm{C}\right)$, cadmium sulphate $(100 \mu \mathrm{M})$, or their combination for $7 \mathrm{~d}$. Then, they were rinsed with distilled water and blotted with tissue paper for fresh mass (f.m.) measurements.

Experiments were carried out using the equipments of the Core Facility of the Karelian Research Center of the Russian Academy of Sciences. Cold tolerance of plants was evaluated by a temperature which induced death of $50 \%$ of palisade cells of leaf mesophyll after $5 \mathrm{~min}$ exposure to testing temperature $\left(\mathrm{LT}_{50}\right)$ in a TZhR-02-20 thermoelectric microcooler (Interm, Moscow, Russia). Temperature was lowered at an interval of about $0.4{ }^{\circ} \mathrm{C}$ (Talanova et al. 2009). Viability of palisade cells was determined in a LOMO Micmed-2 light microscope (LOMO, Moscow, Russia) according to coagulation of cytoplasm and chloroplast disruption.

Lipid peroxidation was estimated spectrophotometrically by determining malondialdehyde (MDA) formed in leaves using the thiobarbituric acid method according to Stewart and Bewley (1980). Leaves (0.1 g) were homogenized with $2 \mathrm{~cm}^{3}$ of $5 \%(\mathrm{~m} / \mathrm{v})$ thiobarbituric acid in $20 \%(\mathrm{~m} / \mathrm{v})$ trichloracetic acid and centrifuged at $10000 \mathrm{~g}$ and $4{ }^{\circ} \mathrm{C}$ for $15 \mathrm{~min}$. The mixture was heated at $95{ }^{\circ} \mathrm{C}$ in a water bath for $30 \mathrm{~min}$, cooled quickly in an ice-bath, and centrifuged at $10000 \mathrm{~g}$ for $5 \mathrm{~min}$. Absorbance of the supernatant was measured at $532 \mathrm{~nm}$ and corrected for a non-specific turbidity by subtracting the absorbance at $600 \mathrm{~nm}$. Malondialdehyde content was calculated using a coefficient of absorbance of $155 \mathrm{mM}^{-1} \mathrm{~cm}^{-1}$.

Proline analysis was performed according to Bates et al. (1973). Wheat leaves $(0.5 \mathrm{~g})$ were homogenized in $3 \%(\mathrm{~m} / \mathrm{v})$ sulfosalicylic acid, and the homogenate was centrifuged at $5100 \mathrm{~g}$ for $5 \mathrm{~min}$. A reaction mixture, which consisted of $2 \mathrm{~cm}^{3}$ of the supernatant, $2 \mathrm{~cm}^{3}$ of $0.2 \%(\mathrm{~m} / \mathrm{v})$ ninhydrin solution, and $2 \mathrm{~cm}^{3}$ of glacial acetic acid, was incubated in a boiling water bath for $1 \mathrm{~h}$ followed by storage in an ice bath. Proline content was monitored spectrophotometrically at $520 \mathrm{~nm}$ using L-proline as a standard.

Glutathione and three major PCs (PC2, PC3, and PC4) were extracted and analyzed after derivatization by reverse-phase HPLC following the protocol described by Sneller et al. (2000). Leaves were ground in liquid nitrogen. Non-protein thiols were extracted by homogenization of $20 \mathrm{mg}$ leaf material in $2 \mathrm{~cm}^{3}$ of icecold $6.3 \mathrm{mM}$ diethylenetriaminepentaacetic acid (Sigma, St. Louis, USA) and $0.1 \%(\mathrm{~m} / \mathrm{v})$ trifluoroacetic acid (Merck, town?, USA). The homogenate was centrifuged at $10000 \mathrm{~g}$ and $4{ }^{\circ} \mathrm{C}$ for $10 \mathrm{~min}$. The supernatant was filtered. After derivatization with monobromobimane, GSH and PCs were separated on a Phenomenex Luna $5 u$ $\mathrm{C} 18$ column at $37^{\circ} \mathrm{C}$. The sample was injected and eluted with a slightly concave gradient of $12-25 \%$ (v/v) methanol for $15 \mathrm{~min}$, and then a linear gradient of 25 to $50 \%$ methanol from 15 to $50 \mathrm{~min}$. Phytochelatins content was calculated as nanomols of the sulfhydryl equivalent per gram of fresh mass using GSH as a standard (Sigma).

Frozen leaf tissues were homogenized with liquid nitrogen. Total RNA was extracted using a TRizol reagent (Evrogen, Moscow, Russia) as instructed by the manufacturer. The total RNA was treated with RNasefree DNase (Syntol, Moscow, Russia) to remove genomic DNA. The purity of RNA samples and their 
concentrations were determined spectrophotometrically (SmartSpecPlus, Bio-Rad, Hercules, USA): samples with $\mathrm{A}_{260} / \mathrm{A}_{280}$ ratios within $1.8-2.0$ were used for further analysis. The total RNA $(1 \mu \mathrm{g})$ was reverse-transcribed using a $M M L V$ RT kit (Evrogen) following the supplier's recommendations. Real-time quantitative PCR was performed using the iCycler $i Q$ detection system (BioRad). Analyzes were performed using a SYBR Green PCR kit (Evrogen). The PCR conditions consisted of denaturation at $95{ }^{\circ} \mathrm{C}$ for $5 \mathrm{~min}$ followed by 40 cycles of denaturation at $95{ }^{\circ} \mathrm{C}$ for $15 \mathrm{~s}$, annealing at $56{ }^{\circ} \mathrm{C}$ for 40 $\mathrm{s}$, and extension at $72{ }^{\circ} \mathrm{C}$ for $45 \mathrm{~s}$. A dissociation curve was generated at the end of each PCR cycle to verify that a single product was amplified using iCycler $i Q$. To minimize sample variations, mRNA expression of a target gene was normalized relative to the expression of a housekeeping gene actin. The mRNA content of target genes (TaP5CS, TaGS1, and TaPCS1) were quantified in comparison to the actin by the $\Delta \Delta \mathrm{Ct}$ method (Livak and Schmittgen 2001). Primers were designed (using the Primer Design program), and they are listed in Table 1 Suppl.

All experiments were performed at least three times. Data were subjected to analysis of variance and to principal component analysis. Data are presented as means \pm standard errors. The Fisher least significant difference test was used to compare means. Differences at $P \leq 0.05$ were considered as statistically significant.

\section{Results}

The results of our study demonstrate that both the individual and combined effects of the low temperature $\left(4^{\circ} \mathrm{C}\right)$ and $\mathrm{CdSO}_{4}(100 \mu \mathrm{M})$ reduced fresh mass of wheat seedlings (Table 1). On the seventh day, the fresh mass decreased by 40,15 , and $42 \%$ at the low temperature, $\mathrm{CdSO}_{4}$, or their combination, respectively, compared with the control. However, the magnitude of the negative effect due to the "combined stresses" was not additive.

Cold tolerance of the leaf cells of wheat seedlings significantly increased after $1-5 \mathrm{~h}$ at the low temperature and continued to rise reaching a maximum on the sixth to seventh day (Fig. 1A). Interestingly, cadmium treatment also led to an increase in cold tolerance but to a lower extent and reached a maximum after $1 \mathrm{~d}$ of exposure. The combination of the low temperature and $\mathrm{CdSO}_{4}$ induced an increase in cold tolerance after $5 \mathrm{~h}$ of exposure and remained unchanged until the end of the experiment (Fig. 1A).

Additionally, MDA content of leaves increased after $24 \mathrm{~h}$ of $4{ }^{\circ} \mathrm{C}$ exposure and remained increased throughout the experiment (Fig. 1B). In the presence of $\mathrm{CdSO}_{4}$, MDA content increased after $3 \mathrm{~d}$ without any further change. The combined stress induced an increase in MDA content already after $1 \mathrm{~h}$, followed by a further substantial rise (Fig. 1B).

The low temperature, $\mathrm{CdSO}_{4}$, and their combination caused an increase in Pro content of leaves. In particular, Pro accumulation slightly increased within $5 \mathrm{~h}$ of exposure to $4{ }^{\circ} \mathrm{C}$ and dramatically rose after $7 \mathrm{~d}$ up to $67 \mu \mathrm{mol} \mathrm{g}{ }^{-1}$ (f.m.) (Fig. 2A). Cadmium treatment for $5 \mathrm{~h}$ also induced an apparent increase in proline content, however, a significant increase was observed after $7 \mathrm{~d}$ but much less than at the low temperature. In contrast, the combined stress resulted in an increase in leaf Pro content up to $40 \mu \mathrm{mol} \mathrm{g}{ }^{-1}$ (f.m.) on the seventh day (Fig. $2 A$ ).

The increase in GSH content of leaves was noted within $1 \mathrm{~h}$ of $4{ }^{\circ} \mathrm{C}$ exposure alone or in combination with $\mathrm{CdSO}_{4}$, whereas $\mathrm{GSH}$ content decreased during 1 - $7 \mathrm{~d}$ (Fig. 2B). No significant difference in GSH content was observed at a short-term $(1-24 \mathrm{~h}) \mathrm{CdSO}_{4}$ treatment, however, after $2 \mathrm{~d} \mathrm{GSH}$ content dropped, and at the end of the experiment, it was 2 -fold smaller as compared with the initial level.

Analysis of PCs content showed their accumulation within $1 \mathrm{~h}$ at $4{ }^{\circ} \mathrm{C}$, but after $48 \mathrm{~h}$ PCs content did not change during further exposure (Fig. 2C). A rapid increase in PCs content was observed within $1 \mathrm{~h}$ of $\mathrm{CdSO}_{4}$ treatment followed by a further increase up to the seventh day. The combined stress also led to an increase in PCs content, but lower than by $\mathrm{CdSO}_{4}$ alone (Fig. $2 \mathrm{C}$ ).

Table 1. The effect of a low temperature of $4{ }^{\circ} \mathrm{C}$, cadmium sulphate $(100 \mu \mathrm{M})$, and their combination on wheat seedling fresh mass $\left[\mathrm{mg} \mathrm{seedling}^{-1}\right]$. Means \pm SEs, $n=27$; different letters indicate significant differences between treatments at $P<0.05$ (ANOVA).

\begin{tabular}{|c|c|c|c|c|}
\hline Time $[\mathrm{h}]$ & Control & $4^{\circ} \mathrm{C}$ & $\mathrm{CdSO}_{4}$ & $4{ }^{\circ} \mathrm{C}+\mathrm{CdSO}_{4}$ \\
\hline 0 & $159 \pm 3^{g}$ & $159 \pm 3^{g}$ & $159 \pm 3^{g}$ & $159 \pm 3^{g}$ \\
\hline 24 & $186 \pm 8^{\mathrm{e}}$ & $161 \pm 2^{\mathrm{fg}}$ & $180 \pm 5^{\mathrm{e}}$ & $163 \pm 4^{\mathrm{fg}}$ \\
\hline 48 & $223 \pm 5^{c}$ & $162 \pm 4^{\mathrm{fg}}$ & $209 \pm 3^{d}$ & $163 \pm 3^{\mathrm{fg}}$ \\
\hline 96 & $277 \pm 8^{\mathrm{a}}$ & $164 \pm 2^{\text {fg }}$ & $248 \pm 8^{b}$ & $167 \pm 5^{\text {efg }}$ \\
\hline 144 & $289 \pm 9^{a}$ & $168 \pm 2^{\mathrm{fe}}$ & $248 \pm 6^{\mathrm{b}}$ & $169 \pm 3^{\text {efg }}$ \\
\hline 168 & $293 \pm 11^{\mathrm{a}}$ & $175 \pm 3^{\mathrm{e}}$ & $248 \pm 6^{b}$ & $169 \pm 5^{\text {efg }}$ \\
\hline
\end{tabular}


The increase in Pro content in wheat leaves correlated with the accumulation of transcripts of the TaP5CS gene encoding $\Delta^{1}$-pyrroline-5-carboxylate synthase (Fig. 3). An increase in the mRNA content of the TaP5CS gene was observed within $24 \mathrm{~h}$ of exposure to $4{ }^{\circ} \mathrm{C}$ and reached a maximum on the seventh day. The influence of $\mathrm{CdSO}_{4}$ and its combination with the low temperature also led to an enhancement of TaP5CS transcript accumulation but less than under the low temperature alone.

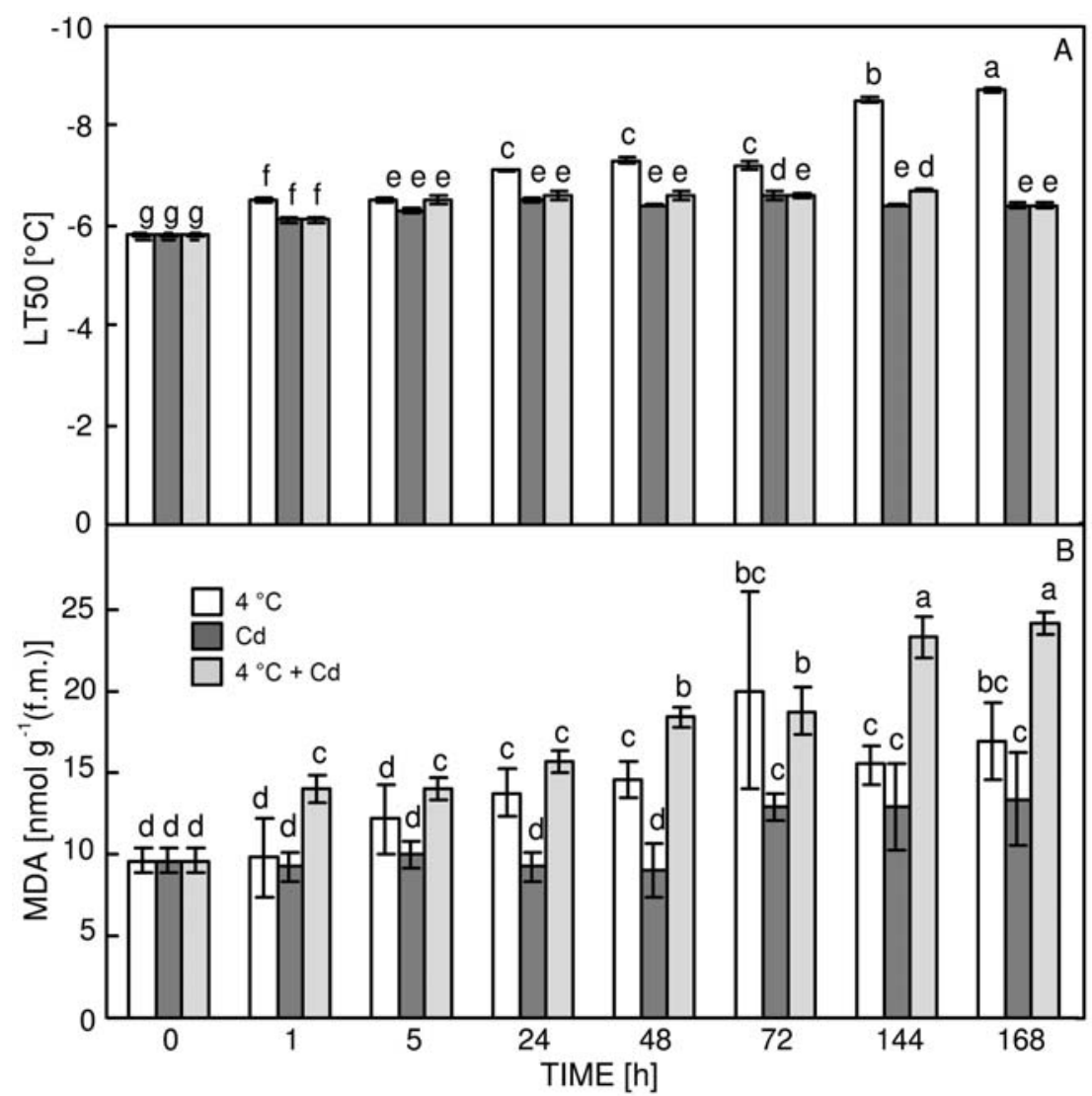

Fig. 1. The effect of a low temperature of $4{ }^{\circ} \mathrm{C}, 100 \mu \mathrm{M} \mathrm{CdSO}_{4}$, and their combination on lethal temperature for $50 \%$ of palisade cells $\left(\mathrm{LT}_{50}\right)(A)$ and malondialdehyde (MDA) content $(B)$ in wheat leaves. Means \pm SEs, $n=18$ for $\mathrm{LT}_{50}$ and $n=12$ for MDA. Different letters indicate significant differences at $P<0.05$ (ANOVA).

The individual and combined effects of the low temperature and $\mathrm{CdSO}_{4}$ led to a higher content of TaGS1 gene transcripts. In particular, such upregulation was apparent within $1 \mathrm{~h}$. The upregulated state of this gene was maintained during $1-7 \mathrm{~d}$. Transcription of TaGS1 did not change after $1 \mathrm{~d}$ of $\mathrm{CdSO}_{4}$ exposure, but it was higher than control on the seventh day. Upregulation of TaGS1 in response to the combination of the low temperature and $\mathrm{CdSO}_{4}$ was not additive (Fig. 3).

Both individual exposure and combined exposure to the low temperature and $\mathrm{CdSO}_{4}$ resulted in accumulation of TaPCS1 gene transcripts. Leaves exposed to $\mathrm{CdSO}_{4}$ or to the low temperature showed TaPCS1 upregulation within $1 \mathrm{~h}$, which rose up to the seventh day (Fig. 3). The combined stress also resulted in the accumulation of TaPCS1 mRNA throughout the experiment.

Principal component analysis was performed to display the maximum amount of variation in a data profile within a few principal components and to understand relations between variables (Fig. 1 Suppl.). As could be expected, physiologically related parameters and processes tended to display correlated output values. The analysis of some parameters considering three types of treatment $\left(4^{\circ} \mathrm{C}\right.$, cadmium, combination of them) showed two components, PC1 accounting for $72.4 \%$ and PC2 representing $23.2 \%$ of total variance. The $\mathrm{PC1}$ was loaded on parameters related to fresh mass, Pro, GSH, and PCs, whereas PC2 was loaded on $\mathrm{LT}_{50}$ and MDA. For instance, GSH, PCs, and MDA accumulations were negatively correlated with LT50, Pro, and fresh mass, whereas a positive correlation was found between PCs content and fresh mass. Moreover, $\mathrm{LT}_{50}$ and Pro content seem to depend on low temperature exposure, PCs content and fresh mass were mainly impacted by cadmium, whereas MDA and GSH were linked to the combined stress (Fig. 1 Suppl.). 


\section{Discussion}

It is generally accepted that environmental stresses are detrimental to plants by reducing their growth and biomass production. However, the inhibition of growth in response to low positive temperatures is one of the prerequisites for the adaptation of winter cereals to cold (Klimov 2009). In the present study, fresh mass of wheat seedlings treated with the low temperature reduced, while their cold tolerance increased. Moreover, accumulation of Pro was observed within $5 \mathrm{~h}$ of low temperature exposure and further increased substantially after $7 \mathrm{~d}$. The results are consistent with the data of Pro involvement in a chilling-induced osmotic stress as a key osmolyte and antioxidant promoting cold tolerance of rape (Gaveliené et al. 2014) and chickpea (Kaur et al. 2011). Moreover, the low temperature induced an increase in TaP5CS mRNA. The highest amount of TaP5CS transcripts correlated with Pro content of leaves. Content of MDA increased at $24 \mathrm{~h}$ under the low temperature but then did not change. These results suggest that proline as well as other non-enzymatic antioxidants played an important role in ROS scavenging and cell protection from oxidative stress.

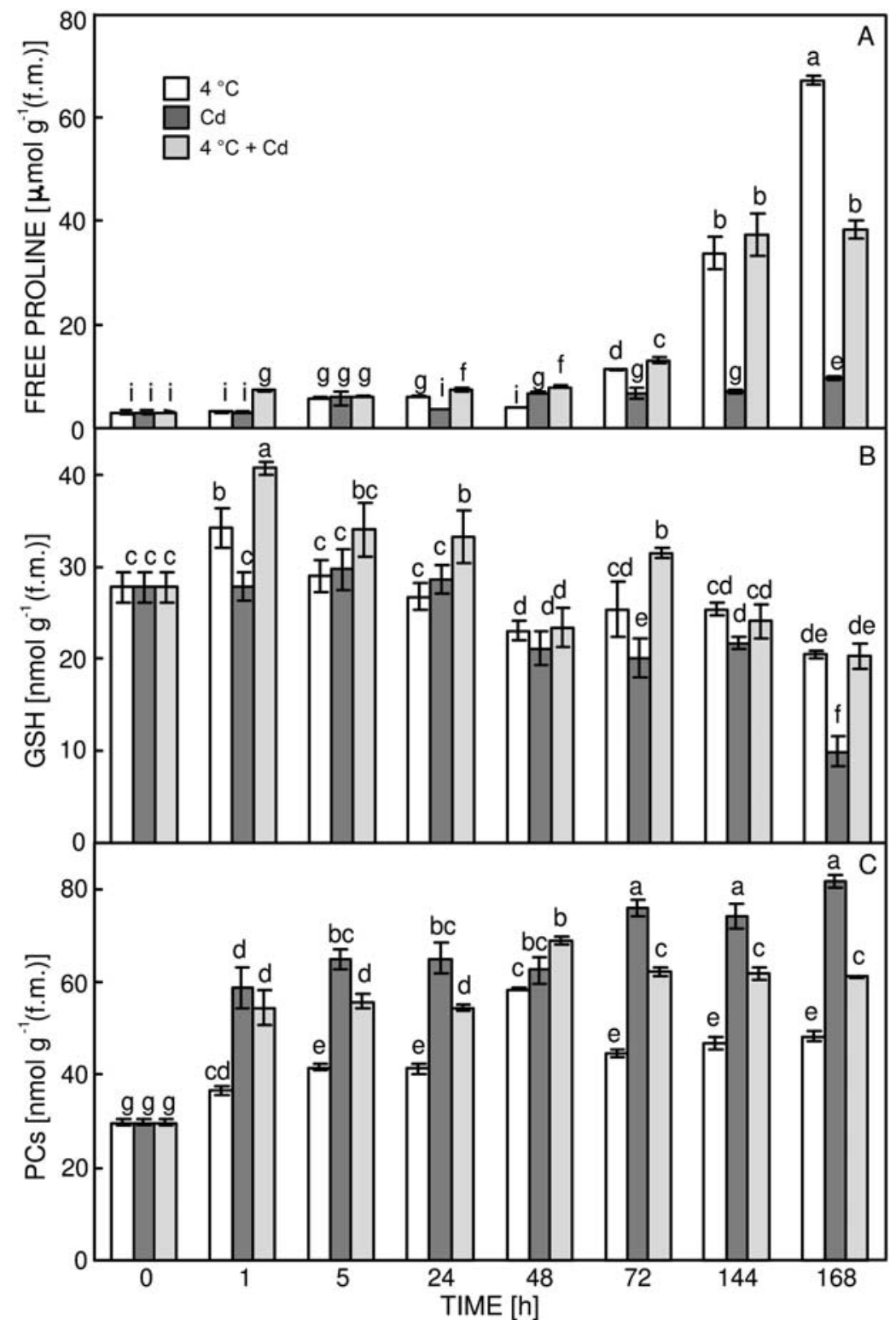

Fig. 2. The effect of a low temperature of $4{ }^{\circ} \mathrm{C}, 100 \mu \mathrm{M} \mathrm{CdSO}_{4}$, and their combination on free proline, reduced glutathione (GSH), and phytochelatins (PCs) content in wheat leaves. Means \pm SEs, $n=12$. Different letters indicate significant differences at $P<0.05$ (ANOVA). 
Along with Pro, GSH is a vital component with multiple roles for eliminating ROS and improving stress adaptation (Noctor et al. 2012, Zagorchev et al. 2013). Our results show that a short-term influence of $4{ }^{\circ} \mathrm{C}$ also led to an increase in PCs. However, PCs content remained enhanced, while GSH content dropped. The decrease in GSH content was most probably due to an increased use of GSH for PCs synthesis. Alternatively, the drop in GSH level could be caused by a presumed competition for glutamate use between GSH and Pro (Fig. 2).

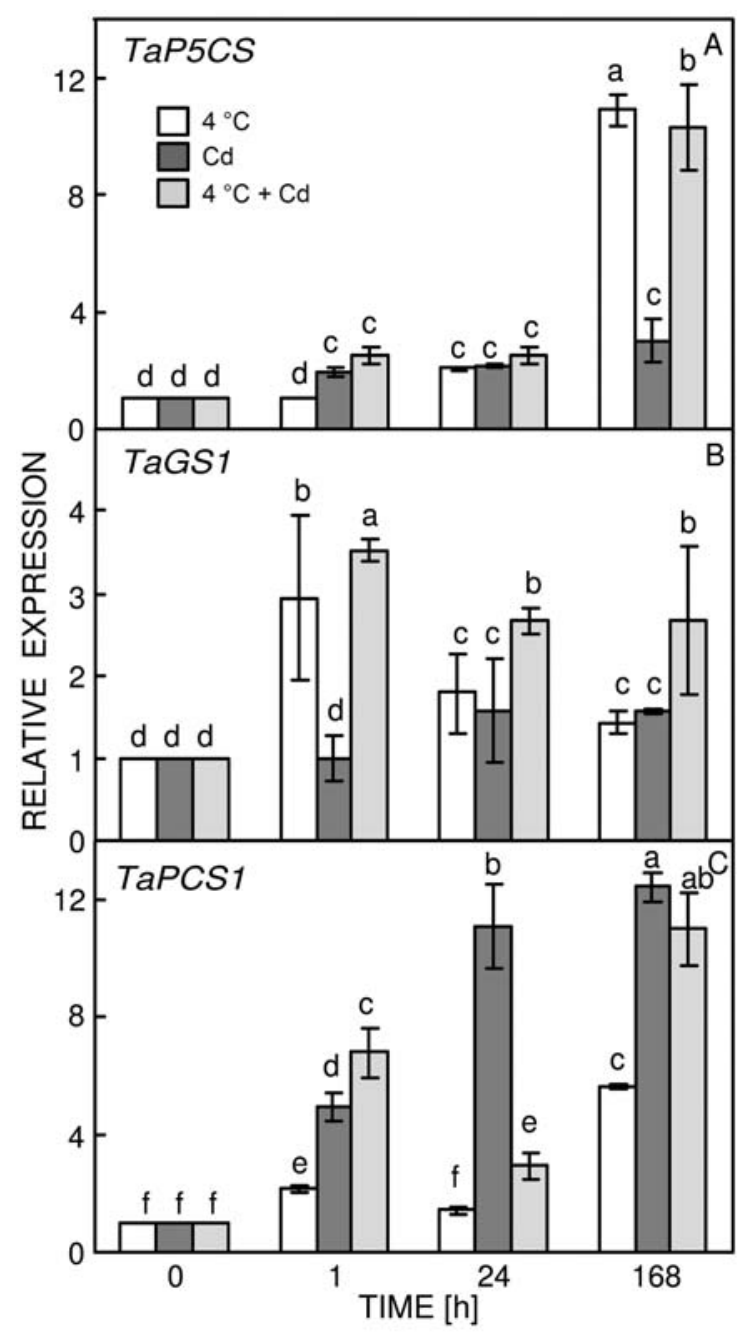

Fig. 3. The effect of a low temperature of $4{ }^{\circ} \mathrm{C}, 100 \mu \mathrm{M} \mathrm{CdSO}_{4}$, and their combination on TaP5CS (A), TaGS1 (B), TaPCS1 (C) gene transcriptions in wheat leaves. An initial gene transcription at $22{ }^{\circ} \mathrm{C}$ is taken as 1 . Means \pm SEs, $n=9$, different letters indicate significant differences between treatments $P<0.05$ (ANOVA).

In plants treated with the low temperature for $7 \mathrm{~d}$, cold tolerance was highest as well as PCs content. Moreover, TaPCS1 transcription in leaves increased at the low temperature and reached the highest level on the seventh day. Numerous studies on PCs have been published but despite an undoubted role in heavy metal stress response, their response to other stresses is unclear. Although, some reports suggested that PCs activity may be affected by stress generally, for example, by a high temperature, salinity (Zagorchev et al. 2013), and UV radiation (Bhargava et al. 2005). Further studies are needed to fully understand their putative role in plant stress response.

Previously, we have noted $\mathrm{Cd}$ accumulation in roots of plants treated with $100 \mu \mathrm{M} \mathrm{CdSO}$ for $1 \mathrm{~h}$ and an increase in Cd accumulation in leaves during the next $7 \mathrm{~d}$ (Repkina et al. 2015). This is typical for wheat as well as for some other plants species which mainly accumulate heavy metals in roots for preventing their entry into the aboveground parts (Kovacs and Szemmelveisz 2017). Nevertheless, cadmium exposure led to a decrease in wheat fresh mass accumulation but less compared with the low temperature (Table 1). The negative effect of $\mathrm{Cd}$ on growth have also been reported by Talanova et al. (2000), Farooq et al. (2013), Li et al. (2013), and Han et al. (2014). Interestingly, an induced cold tolerance in wheat was also detected after $\mathrm{Cd}$ exposure but less than that induced by low temperature. Cadmium as well as other stresses lead to ROS generation that in turn trigger plant ROS-scavenging mechanisms, which include nonenzymatic compounds (Foyer and Noctor 2012). The present research shows that MDA content only slightly changed under $\mathrm{CdSO}_{4}$ treatment, which can be a result of effective ROS scavenging and so prevention of lipid peroxidation. However, $\mathrm{CdSO}_{4}$ caused less Pro accumulation and TaP5CS mRNA content compared to the cold treatment. Apparently, this effect can link to the fact that unlike a low temperature, $\mathrm{CdSO}_{4}$ does not lead to direct osmotic effects and, therefore, not require any accumulation of an osmolyte such as Pro. Perhaps in plants treated with $\mathrm{Cd}$, Pro plays a relatively minor role in stress tolerance.

Our data indicate that $\mathrm{Cd}$ caused a greater decrease in GSH content compared to $4{ }^{\circ} \mathrm{C}$ but resulted in a greater increase in PCs accumulation. Several reports have noted the increase in PCs under heavy metal stress as key chelators (Pal and Rai 2010, Gallego et al. 2012). Also, TaPCS1 gene expression was correlated with PCs accumulation under stress. On the contrary, the dramatic drop in GSH amount could be caused by a direct GSH involvement in cadmium detoxification and simultaneously for PCs synthesis. Though, TaGS1 gene transcripts were elevated during 7 days in cadmium treated plants. These results suggest that under cadmium stress, in contrast to the chilling effect, glutamate is more used for GSH synthesis than for Pro synthesis.

We noted that wheat response to a combination of the low temperature and $\mathrm{CdSO}_{4}$ was similar to that to the low temperature alone. This stress combination significantly reduced $\mathrm{Cd}$ accumulation in wheat in comparison with $\mathrm{CdSO}_{4}$ alone (data not shown). This can be caused by an effect of low temperature on nutrient transport in plants 
although a decrease in fresh mass and an elevated MDA content in wheat were documented.

A significant increase in Pro and PCs content was also induced by the combination of the low temperature and $\mathrm{Cd}$, but it was less than at the low temperature or $\mathrm{CdSO}_{4}$ alone (Fig. 2). Also the combined effect of these factors led to TaP5CS, TaPCS1, and TaGS1 transcript accumulations. A drop in GSH content was also observed but lower than that at cadmium stress alone. Thus, it is suggested that there was no acute substrate competition, and glutamate was used for synthesis of both Pro and GSH because Pro is needed as an osmolyte, and nonprotein thiols as key chelators for heavy metal detoxification.

In the present study, an increase in wheat cold tolerance was observed under a combined effect of low temperature and cadmium, but it did not reach the level obtained by cold exposure alone, which can be a consequence of cadmium toxicity to plant cells and tissues. According to our results, the combined stresses impact did not lead to an additive effect. Therefore, their combination should be regarded as a new state of abiotic stress in plants. However, an interaction between low temperature and cadmium seems to be predominantly controlled by low temperature, which contributes more to the occurrence of stress. The increase of some metabolites with multiple functions (Pro, GSH, and PCs) associated with plant defense mechanisms should contribute to the plant protection from both an individual stress as well as combined stresses. Assessing their physiological responses and adaptive mechanisms under combined rather than individual stresses may prove to be more useful since plants are often exposed to multiple stresses in their natural environment.

\section{References}

Anjum, N.A., Ahmad, I., Mohmood, I., Pacheco, M., Duate, A.C., Pereira, E., Umar, S., Ahmad, A., Khan, N.A., Iqbal, M., Prasad, M.N.V.: Modulation of glutathione and its related enzymes in plants responses to toxic metal and metalloids. - Environ. exp. Bot. 75: 307-324, 2012.

Bates, L.S., Waldren, R.P., Teare, I.D.: Rapid determination of free proline for water stress studies. - Plant Soil 39: 205207, 1973.

Bhargava, P., Srivastava, A.K., Urmil, S., Rai, L.C.: Phytochelatin plays a role in UV-B tolerance in $\mathrm{N}_{2}$-fixing cyanobacterium Anabaena doliolum. - J. Plant Physiol. 162: 1220-1225, 2005.

Chen, A., Komives, E.A., Schroeder, J.I.: An improved grafting technique for mature Arabidopsis plants demonstrates longdistance shoot-to-root transport of phytochelatins in Arabidopsis. - Plant. Physiol. 141: 108-120, 2006.

Delorme-Hinoux, V., Bangash, S.A.K., Meyer, A.J., Reichheld, J.P.: Nuclear thiol redox systems in plants. - Plant Sci. 243: 84-95, 2016.

Diaz-Vivancos, P., De Simone, A., Kiddle, G., Foyer, C.H.: Glutathione - linking cell proliferation to oxidative stress. Free Radical Biol. Med. 89: 1154-1164, 2015.

Farooq, M.A., Ali, S., Hameed, A., Ishaque W., Mahmood, K., Iqbal, Z.: Alleviation of cadmium toxicity by silicon is related to elevated photosynthesis, antioxidant enzymes; suppressed cadmium uptake and oxidative stress in cotton. Ecotoxicol. Environ. Safety 96: 242-249, 2013.

Foyer, C.H., Noctor, G.: Managing the cellular redox hub in photosynthetic organisms. - Plant Cell Environ. 35: 199201, 2012.

Gallego, S.M., Pena, L.B., Barcia, R.A., Azpilicueta, C.E., Iannone, M.F., Rosales, E.P., Zawoznik, M.S., Groppa, M.D., Benavides, M.P.: Unravelling cadmium toxicity and tolerance in plants: insight into regulatory mechanisms. Environ. exp. Bot. 83: 33-46, 2012.

Gaveliené, V., Pakalniškyté, L., Novickiené, L.: Regulation of proline and ethylene levels in rape seedlings for freezing tolerance. - Cent. Eur. J. Biol. 9: 1099-1107, 2014.

Gill, S.S., Anjum, N.A., Hasanuzzaman, M., Gill, R., Trivedi, D.K., Ahmad, I., Pereira, E., Tuteja, N.: Glutathione and

glutathione reductase: A boon in disguise for plant abiotic stress defense operations. - Plant Physiol. Biochem. 70: 204-212, 2013.

Han, Y., Sa, G., Sun, J., Shen, Z., Zhao, R., Ding, M., Deng, S., Lu, Y., Zhang, Y., Shen, X., Chen, S.: Overexpression of Populus euphratica xyloglucan endotransglucosylase/ hydrolase gene confers enhanced cadmium tolerance by the restriction of root cadmium uptake in transgenic tobacco. Environ. exp. Bot. 100: 74-83, 2014.

Kaur, G., Asthir, B.: Proline: a key player in plant abiotic stress tolerance. - Biol. Plant. 59: 609-619, 2015.

Kaur, G., Kumar, S., Thakur, P., Malik, J.A., Bhandhari, K., Sharma, K.D., Nayyar, H.: Involvement of proline in response of chickpea (Cicer arietinum L.) to chilling stress at reproductive stage. - Sci. Hort. 128: 174-181, 2011.

Kishor, P.B.K., Sreenivasulu, N.: Is proline accumulation per se correlated with stress tolerance or is proline homeostasis a more critical issue. - Plant Cell Environ. 37: 300-311, 2013.

Klimov, S.V.: Freezing tolerance of winter wheat plants depends on adaptation of photosynthesis and respiration in different time intervals. - Biol. Bull. 36: 259-266, 2009.

Kovacs, H., Szemmelveisz, K.: Disposal option for polluted plants grown on heavy metal contaminated brownfield lands. - Chemosphere 166: 8-20, 2017.

Li, Q., Lu, Y., Shi, Y., Wang, T., Ni, K., Xu, L., Liu, S., Wang, L., Xiong, Q., Giesy, J.P.: Combined effects of cadmium and fluoranthene on germination, growth and photosynthesis of soybean seedlings. - J. Environ. Sci. 25: 1936-1946, 2013.

Livak, K.J., Schmittgen, T.D.: Analysis of relative gene expression data using real-time quantative PCR and the $2^{-\Delta \Delta C t}$ method. - Methods 25: 402-408, 2001.

Nakabayashi, R., Saito, K.: Integrated metabolomics for abiotic stress responses in plants. - Cur. Opin. Plant Biol. 24: 10-16, 2015.

Noctor, G., Mhamdi, A., Chaouch, S., Han, Y., Neukermans, J., Marquez-Garcia, B., Queval, G., Foyer, C.H.: Glutathione in plants: an integrated overview. - Plant Cell Environ. 35: 454-484, 2012.

Pal, R., Rai, J.P.N.: Phytochelatins: peptides involved in heavy 
metal detoxification. - Appl. Biochem. Biotechnol. 160: 945-963. 2010

Pivato, M., Fabrega-Prats, M., Masi, A.: Low-molecular-weight thiols in plants: Functional and analytical implications. Arch. Biochem. Biophys. 560: 83-99, 2014.

Rejeb, K.B., Abdelly, C., Savoure, A.: How reactive oxygen species and proline face stress together. - Plant Physiol. Biochem. 80: 278-284, 2014.

Repkina, N.S., Batova, Yu.V., Titov, A.F., Talanova, V.V.: [Glutathione Synthetase (GS3) gene expression in the leaves and roots of wheat seedlings under cadmium impact] Trans. Karel. Res. Centre Rus. Acad. Sci. Exp. Biol. 11: 6775, 2015. [In Russ.]

Sneller, F.E.C., Van Heerwaarden, L.M., Koevoets, P.L.M., Vooijs, R., Schat, H., Verkleij, A.C.: Derivatization of phytochelatins from Silene vulgaris, induced upon exposure to arsenate and cadmium: comparison of derivatization with Ellman's reagent and monobrombimane. - J. Agr. Food Chem. 48: 4014-4019, 2000.

Stein, H., Honig, A., Miller, G., Erster, O., Eilenberg, H., Csonka, L.N., Szabados, L., Koncz, C., Zilberstein, A.: Elevation of free proline and proline-rich protein levels by simultaneous manipulations of proline biosynthesis and degradation in plants. - Plant Sci. 181: 140-150, 2011.

Stewart, R.R.C., Bewley, J.D.: Lipid peroxidation associated with accelerated aging of soybean axes. - Plant Physiol. 65: 245-248, 1980.

Talanova, V.V., Titov, A.F., Boeva, N.P.: Effect of increasing concentrations of lead and cadmium on cucumber seedlings. - Biol. Plant. 43: 441-444, 2000.

Talanova, V.V., Titov, A.F., Topchieva, L.V., Malysheva, I.E., Venzhik, Yu.V., Frolova, S.A.: Expression of WRKY transcription factor and stress protein genes in wheat plants during cold hardening and ABA treatment. - Russ. J. Plant Physiol. 56: 94-99, 2009.

Waśkiewicz, A., Beszterda, M., Goliński, P.: Nonenzymatic antioxidants in plants. - In: Ahmad, P. (ed.): Oxidative Damage to Plants. Antioxidant Networks and Signaling. Pp. 201-234. Academic Press, Amsterdam - Boston Heidelberg - London - New York - Oxford - Paris - San Diego - San Francisco - Singapore - Sydney - Tokyo 2014.

Zagorchev, L., Seal, C.E., Kranner, I., Odjakova, M.: A central role for thiols in plant tolerance to abiotic stress. - Int. J. mol. Sci. 14: 7405-7432, 2013. 